\title{
Effects of UCS predictability in GSR conditioning ${ }^{1}$
}

\author{
FRANCES A. HILL, ${ }^{2}$ University \\ Montana, Missoula, Mont. 59801
}

Forty Ss were given 14 partially reinforced acquisition trials followed by 8 extinction trials, using a classical GSR conditioning procedure. For one group, the occurrence or nonoccurrence of the UCS was predictable, while this was not the case for the other group. Results indicated that UCS predictability led to significantly lower response magnitude.

The investigation of the role of cognitive processes (set and attitude) in human conditioning has been prevalent in the literature for a number of years. In an early statement regarding this kind of research, especially work with the galvanic skin response (GSR), Mowrer (1938) concluded that many of the subsidiary facts discovered in conditioning "... are due simply to changes in the nature and extent of the subject's preparedness or readiness to make the particular response under investigation and have no relation to learning proper [p. 88]."

The extent to which cognitive factors contribute to the behavior observed in the GSR conditioning situation has been the central concern of a number of subsequent studies. A major problem in this kind of research appears to be the questionable effectiveness of the instructional set as it is typically administered. It seems that, all too often, investigators assume that whenever they choose to administer a set, $\mathrm{S}$ will be prepared to accept it and to behave accordingly. This criticism is particularly applicable in the case where instructions are given only after $S$ has experienced a series of trials (e.g., the typical extinctioninstructions experiment). In such a situation, it seems reasonable to assume that $S$ has already adopted certain sets and attitudes based upon his interpretation of the situation, and that the set induced by $\mathrm{E}$ is contaminated by being superimposed upon this. Ome (1962) has rather convincingly discussed the problem-solving aspects of the psychological experiment, and in light of his discussion, it seems naive to assume that $S$ waits patiently for $E$ to give him a set before deciding certain things about the situation in which he finds himself.

One approach to this problem would be to give all instructions prior to beginning the session. This would seem to create a uniform set, and reduce some of the need for problem-solving activity on S's part. Although there are some examples of such a procedure in the literature (e.g., Hill, 1967; Peeke \& Grings, 1968), the studies were not designed in such a way as to permit assessment of the specific effects of reduced problem-solving activity.

It was the purpose of the present study to consider the feasibility of another kind of approach, with major emphasis on studying the effects of reducing the need for problem solving. Two groups were treated alike in all respects except in the degree to which the occurrence of the shock-UCS was predictable. Prior to beginning the session, both groups were given a full description of GSR conditioning and of the events to be experienced during the session. For one group, however, the opportunity existed for complete prediction of the presence or absence of the shock-UCS from trial to trial, while for the other group, this opportunity was not available. Based upon the assumption that problem-solving activity is reflected in the response magnitude typically observed, it was hypothesized that CR magnitude would be lowered significantly by providing information which would reduce the need for this kind of activity.

\section{SUBJECTS}

The Ss were 42 students from the introductory psychology class who volunteered for this experiment to fulfill a course requirement. There were 34 males and 8 females, with the sexes being approximately equally represented in the two groups. There were $21 \mathrm{Ss}$ in each of the two groups.

\section{APPARATUS}

The time relations and durations of the CS and UCS were controlled by Hunter timers. The CS was a $1,000-c p s$ tone at $40 \mathrm{~dB}$, produced by a Hewlett-Packard oscillator, Model 202C, and was of 0.6-sec duration. The UCS was a shock produced by an Applegate constant-current stimulator, Model 250, and was delivered through electrodes attached to the tips of the index and middle fingers of S's right hand. The duration of the shock was $0.1 \mathrm{sec}$, terminating simultaneously with the CS. The GSR was picked up from the palm and back of S's left hand through standard Fels zinc electrodes filled with Sanborn Redux Creme. It was amplified and monitored by means of a Fels dermohmmeter, Model 22A, and recorded visually from a dial on the face of the instrument as well as on an Esterline-Angus milliammeter. The $\mathrm{S}$ and the control equipment were located in adjacent, partially sound-deadened rooms. Every trial was initiated automatically by a Gerbrands tape programmer. The intertrial interval ranged randomly from 25 to $45 \mathrm{sec}$, with a mean of $35 \mathrm{sec}$.

\section{PROCEDURE}

Two panels, one of which read Yes and the other No when illuminated, were located $3 \mathrm{ft}$ directly in front of $S$. A partial-reinforcement procedure was used during acquisition, and for Group 1, the Yes and No lights were completely predictive of whether or not shock would occur. Group 2 received the same number of Yes's and No's during acquisition as did Group 1, but they were arranged in such a way as to be neither positively nor negatively correlated with the occurrence of shock. Both groups were shown the No light prior to each extinction trial.

After seating $S$ and attaching the electrodes, $\mathrm{E}$ gave $\mathrm{S}$ the type-written instructions to read. The first part of these instructions was a detailed description of classical conditioning procedures. The second part was designed to describe accurately the erents they would experience, i.e., three initial presentations of shock alone, followed by trials on which either the tone alone or tone followed by shock would be presented. In addition, Ss were instructed to pay attention to the Yes and No lights, one of which would be lighted prior to every conditioning trial, and that their importance would be discussed after the experiment.

All Ss received three presentations of the shock alone (1.0, 1.2, and $1.4 \mathrm{~mA}), 14$ acquisition trials (Trials $3,5,6,10$, and 12 were nonreinforced), and 8 extinction trials. The Yes or No light for any one trial terminated simultaneously with the CS, stayed off for $8 \mathrm{sec}$, and then the next appropriate light came on. Thus, the interval between Yes or No onset and the initiation of the trial ranged from 17 to $37 \mathrm{sec}$. The strength of the UCS was gradually increased throughout acquisition to a terminal level of $2.5 \mathrm{~mA}$.

The Ss were carefully interviewed after the session, and it was determined that all Group 1 Ss had seen the relationship between the lights and the occurrence of shock, while Group 2 Ss could see no significance in the lights.

\section{RESULTS}

The GSR scores were transformed according to the formula:

$$
\log \left[\left(\frac{1}{R_{a}}-\frac{1}{R_{b}}\right) \times 10^{8}+1\right]
$$

where $\mathbf{R}_{b}$ is the resistance at the moment of initiation of the response, and $R_{a}$ is the resistance at the peak of response. Figure 1 


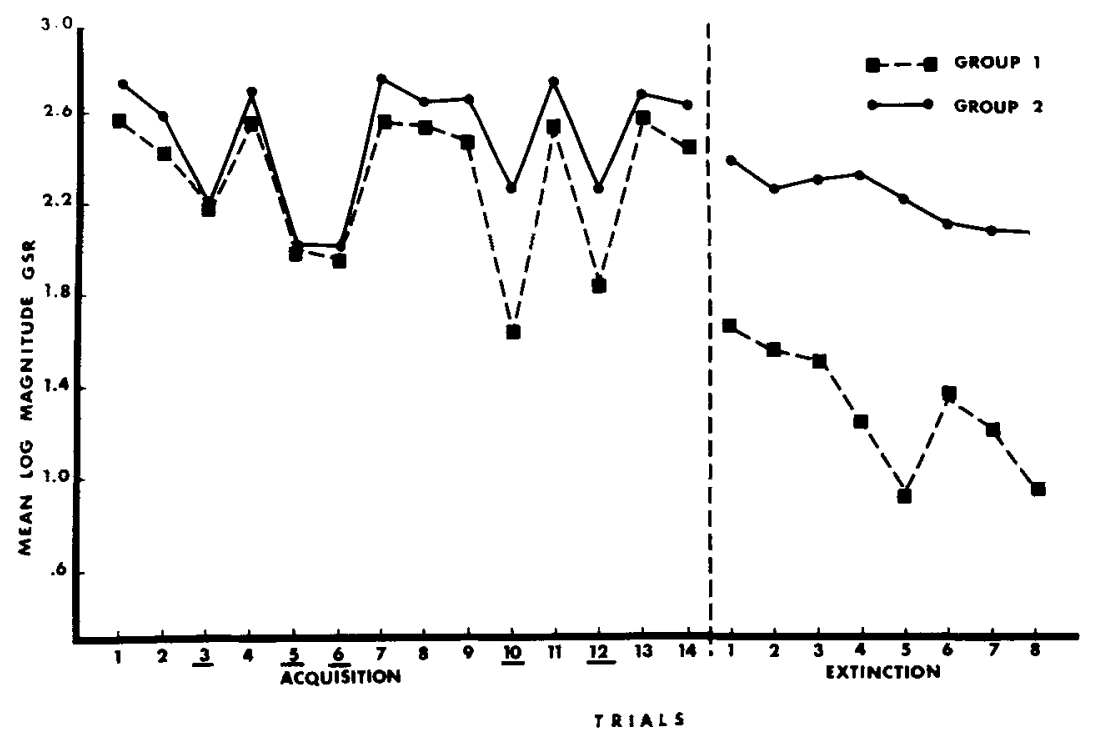

shows the mean log magnitude GSR for both groups throughout acquisition and extinction.

For purposes of analysis, the data were considered in three sections of trials: nonreinforced acquisition, reinforced acquisition, and extinction. A repeated-measures analysis of variance was computed for each of these sections. For nonreinforced acquisition, the Trials by Groups interaction was significant $[F(4,160)=3.12, p<.05]$. As can be seen in Fig. 1 , this arose because of the divergence of the groups after the third nonreinforced trial, with Group 2 responding at a higher level than Group 1. For reinforced acquisition, Group 2 was consistently higher than Group 1, and the overall difference was significant $[F(1,40)=5.29, p<.05]$. Because of this difference between groups on reinforced trials, evident from the very first trial, it was decided to use the ratio of group means (Group 1 $=2.5245$, Group $2=2.6897$ ) as a correction before conducting an analysis of the extinction data. Accordingly, all Group 2 values were multiplied by .938 . The analysis, for which trials were blocked in four blocks of two trials each, revealed a significant main effect of groups $[F(1,40)=12.94, p<.01]$, with Group 2 consistently higher than Group 1. The main effect of trials was also significant $[F(3,120)=6.22, p<.01]$, indicating that extinction was occurring for both groups. The interaction, however, was not significant.
Fig. 1. Mean log magnitude GSR across trials (underlining denotes nonreinforced trials).

information.

The results are also interesting in light of results obtained by Peeke \& Grings (1968). In a GSR conditioning situation, they found UCR decrement as a function of instruction-induced preparatory set, and also found it to be directly related to the degree of predictability in the situation. They did not, however, find CR magnitude differences as a function of predictability. The kind of information they provided their Ss was somewhat different from that in the present study. Specifically, Ss were informed of the CS-UCS relationship, which was constant, variable, or random (unpaired). It may well be that this information served to reduce problem solving with respect to when the UCS would occur, but not with respect to whether it would occur, and consequently, only UCR magnitude was affected. If this is the case, it suggests that the processes involved in the two studies are the same, and that the differences in outcome are a function of the kind of information provided to $S$.

\section{REFERENCES}

HILL, F. A. Effects of instructions and subject's need for approval on the conditioned galvanic skin response. Joumal of Experimental Psychology, 1967, 73, 461-467.

MCALLISTER, W. R., \& MCALLISTER, D. E Effect of knowledge of conditioning upon eyelid conditioning. Joumal of Experimental Psychology, 1958, 55, 579-583.

MOWRER, O. H. Preparatory set (expectancy): A determinant in motivation and learning. Psychological Review, 1938, 45, 62-91.

ORNE, M. T. On the social psychology of the psychological experiment: With particular reference to demand characteristics and their implications. American Psychologist, 1962, 17, 776-783.

PEEKE, S. C., \& GRINGS, W. W. Magnitude of UCR as a function of variability in the CS-UCS relationship. Journal of Experimental Psychology, 1968, 77, 64-69.

WICKENS, D. D., ALLEN, C. K., \& HILL, F. A. Effect of instruction and UCS strength on extinction of the conditioned GSR. Journal of Experimental Psychology, 1963, 66, 235-240. NOTES

1. This study was supported by Grant MH-16349-01 from the National Institute of Mental Health.

2. The author wishes to thank Mr. Frank Meeker and Mr. Terry Loveland for their assistance in data collection. 